\title{
Synthesis and electrochemical evaluation of multivalent va- nadium hydride gels for lithium and hydrogen storage
}

\author{
Leah Morris $^{\mathrm{a}}$, Luke A.C Smith ${ }^{\mathrm{a}}$, Michel L. Trudeau ${ }^{\mathrm{b}}$ and David M. Antonellia*

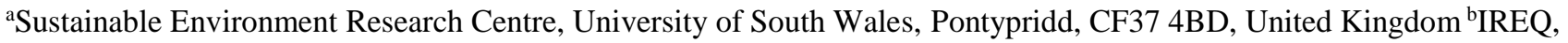 \\ Hydro-Quebec, 1800 Boul. Lionel-Boulet, Varennes, Quebec, J3X 1S1, Canada
}

\section{Supporting Information Placeholder}

\begin{abstract}
A vanadium aryl hydride gel was prepared by thermal decomposition and subsequent hydrogenation of tetraphenyl vanadium and evaluated for electrochemical and hydrogen storage performance. Characterization by IR, XRD, XPS, nitrogen adsorption, and TGA suggests that the material consists predominantly of a mixture of vanadium centers in oxidation states of IIIV bound together by bridging hydride and phenyl groups. Electrochemical properties were explored to probe the reversible oxidation state behavior and possible applications to $\mathrm{Li}$ batteries, with the hypothesis that the low mass of the hydride ligand may lead to superior gravimetric performance relative to heavier vanadium oxides and phosphates. The material shows reversible redox activity and has a promising peak capacity of $131 \mathrm{mAhg}^{-1}$, at a discharge rate of $1 \mathrm{mAcm}^{-2}$, comparable to bulk $\mathrm{VO}_{2}$ samples also tested in this study. After repeated charge discharge cycling for 50 cycles, the material retained $36 \%$ of its capacity. The material also shows improved hydrogen storage performance relative to previously synthesized $\mathrm{VH}_{3}$-based gels, reaching a reversible gravimetric storage capacity of $5.8 \mathrm{wt} \%$ at $130 \mathrm{bar}$ and $25^{\circ} \mathrm{C}$. Based on the measured density, this corresponds to a volumetric capacity of $79.77 \mathrm{kgH}_{2} \mathrm{~m}^{-3}$, demonstrating that the 2017 US DOE system goals of $5.5 \mathrm{wt} \%$ and $40 \mathrm{~kg} \mathrm{H}_{2} \mathrm{~m}^{-3}$ may be achievable upon containment in a Type 1 tank and coupling to a fuel cell.
\end{abstract}

\section{Introduction}

Homoleptic hydrides of the first row transition metals ${ }^{1}$ represent a new frontier in energy storage because of their low molecular weight, electrochemical flexibility, and potential for coordinative unsaturation, a feature that can be exploited in hydrogen or methane storage. The transition metal dihydrides $\mathrm{MH}_{2}\left(\mathrm{M}=\mathrm{Cr}\right.$, ${ }^{2}$ $\mathrm{Mn},{ }^{3} \mathrm{Fe},{ }^{4} \mathrm{Co}$, and $\left.\mathrm{Ni}^{5}\right)$ and trihydrides of the form $\mathrm{MH}_{3}\left(\mathrm{M}=\mathrm{Ti}^{6}\right)$ have been observed as molecular species using matrix isolation techniques at cryogenic temperatures but have never been isolated pure in bulk form. Because of the low cost of vanadium (ca. 15-20 $\mathrm{USD} / \mathrm{kg}$ ) and importance in battery materials of this metal as well as the overall low mass of the hydride ligand, a gravimetric advantage in any energy storage application, the development of general and convenient synthetic routes into vanadium hydrides for energy storage applications would represent an important advance. Metallic vanadium reacts with hydrogen at room temperature and atmospheric pressure to give non stoichiometric monohydrides up to $\mathrm{VH}_{0.9}$. Higher hydrides of vanadium $\left(\mathrm{VH}_{\sim 1.6}\right)$ were prepared by Maeland et al using electrolytic techniques. ${ }^{7}$ Later, the dihydride $\mathrm{VH}_{2}$ was formed by reaction of vanadium with 6.9 bar hydrogen at $450{ }^{\circ} \mathrm{C}$ but this was found to be unstable at room temperature. ${ }^{8}$ From the standpoint of electrochemical energy storage the synthesis of vanadium hydrides in higher oxidation states than II is important because of the greater electron per mole capacities relative to lower oxidation state species, however to the best of our knowledge a pure phase higher hydride such as $\mathrm{VH}_{3}$ or $\mathrm{VH}_{4}$ has never been isolated or characterized in bulk form.

In previous work we explored the potential of homoleptic transition metal alkyl hydrides ${ }^{9}$ for applications in hydrogen storage using the Kubas interaction, ${ }^{10,11}$ a type of $\mathrm{H}_{2}$ binding intermediate in energy between physisoprtion and dissociative hydride-forming pathways. The first example we reported was an amorphous Ti(III) alkyl hydride which had a reversible gravimetric hydrogen storage capacity of $3.49 \mathrm{wt} \%$ at 140 bar and $25{ }^{\circ} \mathrm{C} .{ }^{9 a}$ Improvements in gravimetric capacity to $5.07 \mathrm{wt} \%$ at 160 bar and $5.4 \mathrm{wt} \%$ at 120 bar were later demonstrated in Cr(III) alkyl hydride ${ }^{9 b}$ and V(III) alkyl hydride gels, ${ }^{9 c}$ respectively. Surprisingly, the hydrogen adsorption of the $\mathrm{Cr}$ and $\mathrm{V}$ materials was measured as less than $1 \mathrm{~kJ} \mathrm{~mol}^{-1} \mathrm{H}_{2}$ endothermic, suggesting that the complex heat management systems that thwart applications of hydrides and physisorption materials may not be required for on board applications of these materials. While the hydrogen storage performance and thermodynamic neutrality of the V(III) alkyl hydride suggest that a system based around it may approach the US Department of Energy's (DOE) gravimetric system goal of $5.5 \mathrm{wt} \%$, previous research into battery materials has shown that vanadium compounds perform well as cathode materials for lithium ion batteries. This is particularly true for lightweight high oxidation state vanadium materials as shown by the relative performance of $\mathrm{V}_{2} \mathrm{O}_{5}{ }^{12}$ Lower oxidation state vanadium materials such as $\mathrm{VO}_{2}$ and $\mathrm{V}_{2} \mathrm{O}_{3}$ have also shown potential with initial capacities of $>150$ $\mathrm{mAhg}^{-1} \cdot{ }^{13}$ Thus, related vanadium hydride materials could have significant potential as a lithium battery cathode material as they would possess a number of vanadium centers in the V(IV) or V(III) oxidation states, providing the capacity for lithium insertion. Furthermore, the hydride ligand is considerably lighter than the $\mathrm{O}$ and $\mathrm{P}$ used in traditional vanadium-based battery materials, potentially affording much higher electron per gram energy storage numbers. Fabricating these materials in a nanocrystalline form would be of added benefit because of the potential for pseudocapacitance, ${ }^{14}$ which uses the vast majority of the redox centers situated near the surface to improve the kinetics of the charge transfer reaction due to the shorter diffusion path lengths, leading to a capacitive-like response. ${ }^{15-16}$ A nanocrystalline vanadium hydride may thus be highly desirable as it could potentially pos- 
sess higher energy densities than observed in vanadium oxides and phosphates, but with higher power density due to the faster charge and discharge kinetics afforded by pseudocapacitance.

While hydrogen storage applications of homoleptic vanadium (III) alkyl hydrides have previously been explored by our group, ${ }^{9 c}$ the tris(bis(trimethylsilyl) methyl)vanadium(III) precursor required to prepare the material is prohibitively expensive and difficult to synthesize and the original literature procedure for the synthesis of (tris(bis(trimethylsilyl) methyl)vanadium(III)) reported a recrystallized yield of only $14 \% .{ }^{17}$ Both vanadium trichloride, which is insoluble in all solvents it does not react with, and bis(trimethylsilyl) chloromethane are costly reagents to purchase and the freshly-synthesized $1 \% \mathrm{Na} \mathrm{Li}$ dispersion required to synthesize the necessary alkyl Li reagent is difficult and hazardous to prepare. With an interest in reducing the cost of materials synthesis in order to explore electrochemical applications of vanadium hydrides on a bulk scale, it would be beneficial to explore possible synthesis routes for closely analogous vanadium hydrides starting from inexpensive and ether-soluble $\mathrm{VCl}_{4}$ based on the method of Wilkinson ${ }^{18}$ used for the synthesis of $\left(\mathrm{Me}_{3} \mathrm{SiCH}_{2}\right)_{4} \mathrm{~V}$. Furthermore, based on the 18 electron rule, phase pure $\mathrm{VH}_{4}$ could bind up to $4 \mathrm{H}_{2}$ molecules by the Kubas interaction giving a theoretical maximum gravimetric hydrogen storage value of $14.6 \mathrm{wt} \%$ and an improvement in performance over previous vanadium hydrides prepared by our group. Thus, for the reasons cited above, in this paper we report the synthesis of a multivalent vanadium hydride aryl gel from convenient and inexpensive precursors and explore its properties in electrochemical and hydrogen storage applications.

\section{Experimental}

\section{General}

All chemicals were purchased from Sigma-Aldrich and used without further purification. Manipulations were performed in an argon glove box or on a nitrogen Schlenk line. Reactions with hydrogen were carried out in the solid state using a stainless steel PARR hydrogenation vessel. Grade 6 hydrogen purchased from Air Liquide was used for synthesis and isotherms.

\section{Syntheses}

\section{Preparation of tetraphenyl vanadium}

By analogy to Wilkinson's synthesis of tetrakis (trimethylsilylmethyl) vanadium from $\mathrm{VCl}_{4}$ and the alkyl lithium, ${ }^{13}$ phenyllithium (50 mmol, $25 \mathrm{~mL}$ of a $2.0 \mathrm{M}$ solution in dibutylether) was stirred at room temperature. To this, $\mathrm{VCl}_{4}(2.03 \mathrm{~mL}, 12.5 \mathrm{mmol})$ was added drop wise via a syringe. The reaction mixture turned dark brown in color, increased in temperature and bubbled vigorously. The reaction continued stirring for $15 \mathrm{~min}$ until it had stopped bubbling and had cooled back to room temperature. The mixture was filtered to give a dark brown precipitate and brown filtrate. Because of the well-documented thermal instability of homoleptic alkyl complexes of vanadium, ${ }^{18}$ the putative tetraphenyl vanadium (IV) complex was not isolated, but used immediately in the next synthesis protocol described below.

\section{Preparation of vanadium hydride gel}

The filtrate was immediately transferred to a PARR pressure vessel and stirred under an inert atmosphere for 48 hours at 100 ${ }^{\circ} \mathrm{C}$. The reaction was then filtered to give a black precipitate and the precipitate dried in vacuo for $4 \mathrm{~h}$ at $100{ }^{\circ} \mathrm{C}$ to afford a fine black powder (V(IV)-100) (728 mg). The black powder was then hydrogenated in the PARR vessel at a pressure of 100 bar $\mathrm{H}_{2}$ for $48 \mathrm{~h}$ at $25^{\circ} \mathrm{C}$ and then dried in vacuo for $4 \mathrm{~h}$ at $100{ }^{\circ} \mathrm{C}$ before cooling to room temperature to give a black powder (V(IV)-25C$\mathrm{H}_{2}$ ) (109 mg).

\section{Characterization}

Infrared spectroscopy was conducted on a Perkin Elmer Spectrum RX1 using $\mathrm{KBr}$. Prior to analysis the IR grade $\mathrm{KBr}$ was oven dried overnight at $120^{\circ} \mathrm{C}$ to remove residual water. A blank sample of $\mathrm{KBr}$ was then ground in an oven-dried pestle and mortar in the glovebox and then compressed in air to form a disc. A background was then taken of the blank $\mathrm{KBr}$ disc. Approximately $5 \mathrm{mg}$ of sample was ground with $200 \mathrm{mg} \mathrm{KBr}$ in the glovebox and then compressed in air quickly to form a disc. The spectrum of $\mathrm{KBr}$ was subsequently subtracted from the IR of the sample. Nitrogen adsorption and desorption data were collected at $-196{ }^{\circ} \mathrm{C}$ on a Micromeritics ASAP 2020. A fluid (xylene) displacement method was used $25{ }^{\circ} \mathrm{C}$ to measure the density of the material. The X-ray spectrum was taken using a Bruker Discover diffractometer with $\mathrm{Co} \mathrm{K} \alpha$ radiation. The XPS analysis was performed using a PHI-5500 spectrometer using monochromated Al Ka radiation. The positions of the peaks were referenced to surface $\mathrm{C}-\mathrm{C}$ or $\mathrm{C}-\mathrm{H}$ bound at $284.8 \mathrm{eV}$. The powder was placed on the XPS holder inside an Ar glove box and transferred under Ar to the XPS intro chamber without any exposure to air. For insulating materials, an electron-flooding gun was used to compensate the surface charges. The different chemical contributions for each spectrum were obtained using CasaXPS. The thermogravimetric analysis (TGA) and differential thermal analysis (DTA) was performed in a STA $449 \mathrm{C}$ analyser from Netzsch under a flow of dried air at $10.00{ }^{\circ} \mathrm{C} / \mathrm{min}$ up to $700{ }^{\circ} \mathrm{C}$. Argon was also used to protect the balance section.

\section{Electrochemistry}

Working electrodes of $\mathrm{V}(\mathrm{IV})-25 \mathrm{C}-\mathrm{H}_{2}$ and $\mathrm{VO}_{2}$ consisted of $80 \%$ active material, $10 \%$ super conducting carbon black, and $10 \%$ polyvinylidenefluoride (PVDF) by weight. The electrode paste was made by grinding the active material with carbon black to ensure a good mixture of the powders. The powders were then stirred with PVDF and n-methyl-2-pyrrolidinone (NMP) solvent until a homogenous paste was formed. The paste was spread onto copper foil (current collector). The electrode was dried by first heating to $80{ }^{\circ} \mathrm{C}$ to bake off any excess NMP solvent before increasing the temperature to $120^{\circ} \mathrm{C}$ overnight to allow the electrode material to bind with the current collector. Once completed, the electrodes were punched using a Hohsen electrode punch to produce uniform sized discs of $15 \mathrm{~mm}$. The same procedure was followed for the respective counter and reference electrode of lithium metal foil. The electrolyte used in this investigation is 1.0 $\mathrm{M} \mathrm{LiPF}_{6}$ dissolved in ethylene carbonate (EC) and diethyl carbonate (DEC) solutions at a ratio of 1:1 by volume. Electrochemical cells were assembled in a glove box, and the cell potential window used for these tests was between $1-3.2 \mathrm{~V}$ vs. $\mathrm{Li} / \mathrm{Li}^{+}$. The cyclic voltammetry measurements were carried out at scan rates of $0.5,1,2$ and $5 \mathrm{mvs}^{-1}$ and galvanostatic charge discharge data was recorded at a current density of $1 \mathrm{~mA} \mathrm{~cm}^{-2}$. All measurements were carried out at room temperature using a Hohsen HS flat cell. Electrochemical AC impedance spectra were obtained using the same Li battery cell set up, by applying a sine wave with amplitude of $0.5 \mathrm{mV}$ over the frequency range from $100 \mathrm{KHz}$ to 0.01 $\mathrm{Hz}$. 


\section{Hydrogen adsorption}

Hydrogen adsorption isotherms were obtained by using a computer controlled gas sorption Sieverts apparatus manufactured by Hy-Energy. High purity hydrogen (Grade 6, 99.9999\% purity) purchased from Air Liquide was used. Stainless steel spacers were added to the sample holder along with the material to reduce excess void space. The void space of the sample was calculated by performing a helium volume calibration at $25^{\circ} \mathrm{C}$ using 5 each adsorption and desorption points (total of 10), with outlying values discarded and rerun. Excess hydrogen storage measurements on a $200 \mathrm{mg}$ standard AX-21 sample (0.65 wt. \% at 70 bar and 25 ${ }^{\circ} \mathrm{C}$ ) were performed to ensure correct functioning of the instrument (Figure 4). These measurements are all necessary to ensure the accuracy of the isotherms. The reported gravimetric hydrogen storage capacity of Carbon $\mathrm{AX}-21$ at $25^{\circ} \mathrm{C}$ is $0.3 \mathrm{wt} \%$ at 35 bar. ${ }^{19}$ This corresponds to $0.6 \mathrm{wt} \%$ at 70 bar which gives an error in our measurement of $\pm 0.07 \mathrm{wt} \%((0.65-0.6) \times 100 / 70)$ at 100 bar $\mathrm{H}_{2}$ for a $200 \mathrm{mg}$ sample size of AX-21.

\section{Results and Discussion}

\section{Materials characterization}

To prepare the vanadium hydride, $\mathrm{VCl}_{4}$ was treated with phenyllithium in dibutyl ether and the mixture filtered to give a black solution, which was subsequently stirred at $100{ }^{\circ} \mathrm{C}$ for 48 hours. The ensuing suspension was then filtered to give a black precipitate, which was dried in vacuo at $100{ }^{\circ} \mathrm{C}$ for four hours to afford a black air moisture sensitive solid (V(IV)-100). As illustrated in the reaction mechanism in Scheme 1, we propose that during heat treatment the vanadium aryl precursor polymerizes via a bimolecular C-H activation process with loss of benzene to form an organometallic polymer with bridging phenyl groups. An alternate decomposition route could also involve multiple bond homolysis reactions or to form two equivalents of biphenyl and vanadium metal, however the IR evidence discussed below confirms the presence of hydrocarbon in the polymer, supporting our assignment as an organometallic polymer rather than vanadium metal. The material V(IV)-100 was then treated with hydrogen at 100 bar for 48 hours at $25{ }^{\circ} \mathrm{C}$ to give $\mathrm{V}(\mathrm{IV})-25 \mathrm{C}-\mathrm{H}_{2}$. In this step, we propose that bridging phenyl ligands are replaced with bridging hydrides via the well documented hydrogeneolysis reaction to form a polymeric vanadium(IV) hydride material.<smiles>Clc1ccccc1</smiles>
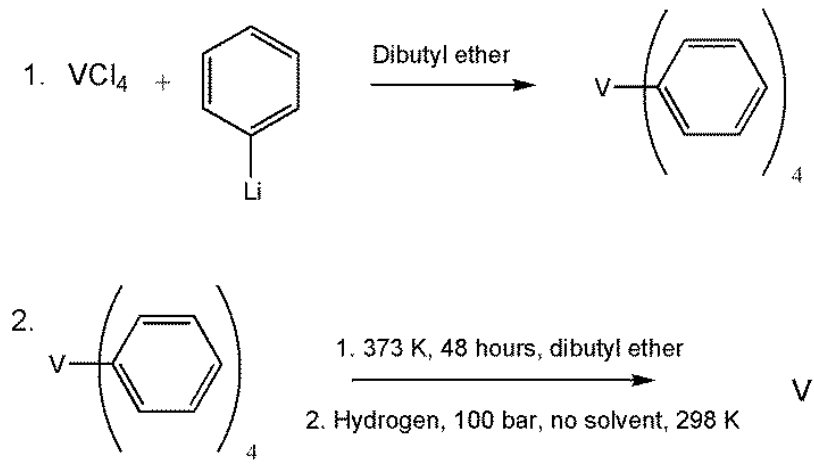

$\mathrm{VH}_{\mathrm{x}}$

Scheme 1. Proposed mechanism for the synthesis of vana$\operatorname{dium}($ IV) hydride

Infrared spectroscopy was used to gauge the loss of hydrocarbon on hydrogenation of V(IV)-100 by observing the relative intensity of the C-H stretch in the $2900-2960 \mathrm{~cm}^{-1}$ region. The infrared spectra of $\mathrm{V}(\mathrm{IV})-100$ and $\mathrm{V}(\mathrm{IV})-25 \mathrm{C}-\mathrm{H}_{2}$ are shown in figure S1. For V(IV)-100 there are C-H stretches at 2958, 2919 and $2868 \mathrm{~cm}^{-1}$. The intensity of the $\mathrm{C}-\mathrm{H}$ stretches decrease slightly after room temperature hydrogenation at 70 bar as the hydrocarbon ligands are replaced by hydrides as a result of hydrogeneolysis. Typically transition metal-hydride bands appear in the region of $1900 \pm 300 \mathrm{~cm}^{-1}$ however they can often be weak in intensity and appear at lower frequency in the case of bridging. ${ }^{20} \mathrm{In}$ the spectrum of $\mathrm{V}(\mathrm{IV})-25 \mathrm{C}-\mathrm{H}_{2}$ there is a stretch in this $\mathrm{M}-\mathrm{H}$ region at $1633 \mathrm{~cm}^{-1}$ with a weak shoulder at $1575 \mathrm{~cm}^{-1}$. However, in $\mathrm{KBr}$, water displays a band at $1647 \mathrm{~cm}^{-1}$ in addition to usual the diagnostic broad band at $3300 \mathrm{~cm}^{-1}$, which is also observed in the spectra of both vanadium samples from trace water absorbed by the $\mathrm{KBr}$ disc during the rapid transfer step from the glove box to IR apparatus, so the expected V-H stretch in the spectrum of V(IV)-25C-H may be the shoulder at $1575 \mathrm{~cm}^{-1}$ or could also be totally obscured by the $\mathrm{O}-\mathrm{H}$ stretch at $1647 \mathrm{~cm}^{-1}$.

Nitrogen adsorption-desorption isotherms of V(IV)-100 and $\mathrm{V}(\mathrm{IV})-25 \mathrm{C}-\mathrm{H}_{2}$ were recorded at $77 \mathrm{~K}$ and are shown in figures $\mathrm{S} 2$ and S3 respectively. In both materials the nitrogen adsorption isotherms can be described as type II in nature. The lack of a significant increase in slope between 0 and $0.1 \mathrm{P} / \mathrm{P}_{0}$ suggests that there is very little microporosity in either material, however the increasing slope between 0.8 and $1.0 \mathrm{P} / \mathrm{P}_{0}$ indicates the presence of significant textural porosity. The surface area of $\mathrm{VH}-100$ is 0.6 $\mathrm{m}^{2} / \mathrm{g}$. After hydrogenating this material in the solid state to form $\mathrm{V}(\mathrm{IV})-25 \mathrm{C}-\mathrm{H}_{2}$ the surface area increases to $2.2 \mathrm{~m}^{2} / \mathrm{g}$. The small increase in surface area may be due to loss of hydrocarbon from the material forming new porous pathways through the nanostructure. The low surface area and lack of porosity is similar to what was observed for the vanadium hydride gel derived previously from a V(III) alkyl precursor, ${ }^{9 \mathrm{c}}$ but differs from the $\mathrm{CrH}_{3}{ }^{9 \mathrm{~b}}$ and $\mathrm{TiH}_{3}{ }^{9 \mathrm{a}}$ materials, which possess significant microporosity and surface areas ranging from $300-500 \mathrm{~m}^{2} \mathrm{~g}^{-1}$, suggesting a more closely packed structure in the vanadium hydrides.

The powder X-ray diffraction pattern is shown in figure S4. Apart from a low angle reflection suggestive of some mesoscopic order and some small reflections from $25-35^{\circ}$ that correspond to the glass capillaries, the majority of the diffraction range does not give rise to reflections establishing that the sample is largely amorphous. This is not surprising as the $\mathrm{Ti},{ }^{9 \mathrm{a}} \mathrm{Cr},{ }^{9 \mathrm{~b}}$ and previously synthesized $\mathrm{V}^{9 \mathrm{c}}$ hydride analogues are also amorphous and the vanadium region of the XPS discussed below indicates that multiple vanadium species in different oxidation states are present in the material.

Thermogravimetric analysis (TGA) was carried out on V(IV)100 and $\mathrm{V}(\mathrm{IV})-25 \mathrm{C}-\mathrm{H}_{2}$ to determine the percentage of hydrocarbon remaining in each material after thermal precipitation and subsequent hydrgoeneolysis. The TGA and DTA curves of V(IV)100 and $\mathrm{V}(\mathrm{IV})-25 \mathrm{C}-\mathrm{H}_{2}$ are thus shown in figures S5 and S6, respectively. For V(IV)-100, as the temperature increases from room temperature to $563{ }^{\circ} \mathrm{C}$ the mass of the sample decreases by $27.5 \%$ due to combustion of remaining phenyl ligands in the material. This is also observed in the DTA curve where there is a broad peak centered at $548{ }^{\circ} \mathrm{C}$. Above $563{ }^{\circ} \mathrm{C}$ the mass of the material stabilizes at $72.5 \%$ of the original mass. In the TGA plot of $\mathrm{V}(\mathrm{IV})-25 \mathrm{C}-\mathrm{H}_{2}$ the weight loss occurs more rapidly from 298 $376{ }^{\circ} \mathrm{C}$ where an exotherm centered at $371{ }^{\circ} \mathrm{C}$ is observed in the DTA plot. Beyond this temperature the mass of the sample decreases more slowly up to $572{ }^{\circ} \mathrm{C}$, where an exotherm is observed in the DTA plot centered at $564{ }^{\circ} \mathrm{C}$. As the temperature rises further to $685{ }^{\circ} \mathrm{C}$ the curve plateaus with $83.7 \%$ of the original sample mass remaining, compared to $72.5 \%$ for V(IV)-100, confirming that solid-state hydrogenation indeed leads to reduction in the amount of hydrocarbon. Since V(IV)-25C-H $\mathrm{H}_{2}$ is still $16.3 \%$ hydrocarbon by weight, solid-state hydrogenation for longer periods or at higher temperatures and pressures may drive the re- 
placement of phenyl ligands with hydrides further to completion. While the precise molecular formula of these two materials cannot be determined from the TGA data because of the unknown composition of the final combustion product arising from ambiguous oxidation states and possible vanadium carbide formation, the sum of our data is consistent with the formulation of V(IV)-25C$\mathrm{H}_{2}$ as a vanadium aryl hydride with the general formula $\mathrm{VH}_{\mathrm{x}}$ $\mathrm{y}\left(\mathrm{C}_{6} \mathrm{H}_{5}\right)_{\mathrm{y}}$.

X-Ray photoelectron spectroscopy (XPS) was carried out to determine the oxidation states of the vanadium species present in $\mathrm{V}(\mathrm{IV})-100$ and $\mathrm{V}(\mathrm{IV})-25 \mathrm{C}-\mathrm{H}_{2}$ and the data is shown in figures 1 and 2, respectively, with the base line corrected XPS figures displayed in S7 and S8. In the vanadium $2 p / 3$ region of V(IV)-100 there is a broad emission centered around $516 \mathrm{eV}$, consistent with an average oxidation state of V(IV). Peak fitting of this emission demonstrates that there are multiple oxidation states of vanadium present in the material. A vanadium (V) species can be simulated at $516.9 \mathrm{eV}$ while the simulated emission at $515 \mathrm{eV}$ can be assigned to $\mathrm{V}(\mathrm{V})$ by comparison to the XPS of $\mathrm{V}_{2} \mathrm{O}_{5}{ }^{21}$ The simulation at $515.3 \mathrm{eV}$ can be attributed to a V(III) species as it is close in value to the emission reported for $\mathrm{VCl}_{3}$ at $515 \mathrm{eV} .^{22}$ After hydrogenation of $\mathrm{V}(\mathrm{IV})-100$ to give $\mathrm{V}(\mathrm{IV})-25 \mathrm{C}-\mathrm{H}_{2}$ the broad emission moves to $513 \mathrm{eV}$ as shown in figures 1 and 2. Peak fitting of this emission demonstrates that there are still multiple oxidation

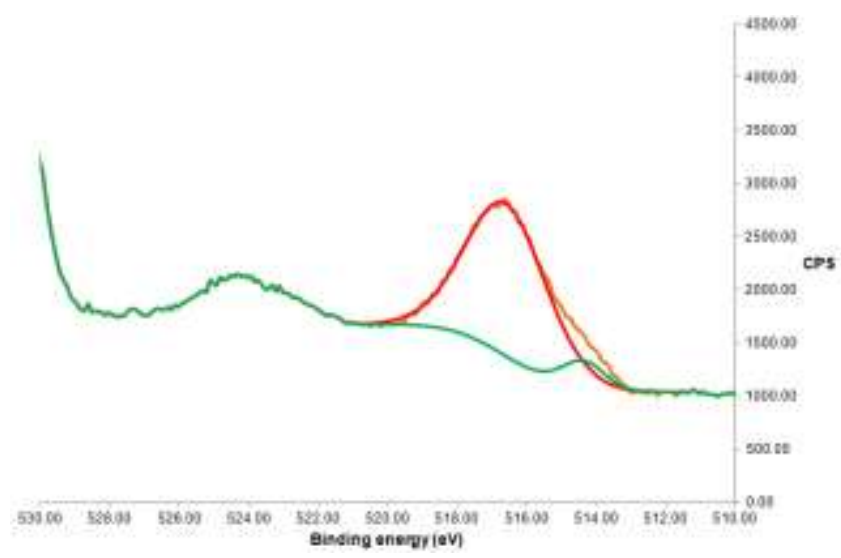

Figure 1 . Peak fitting of vanadium $2 \mathrm{p} 3 / 2$ region of XPS of V(IV)100

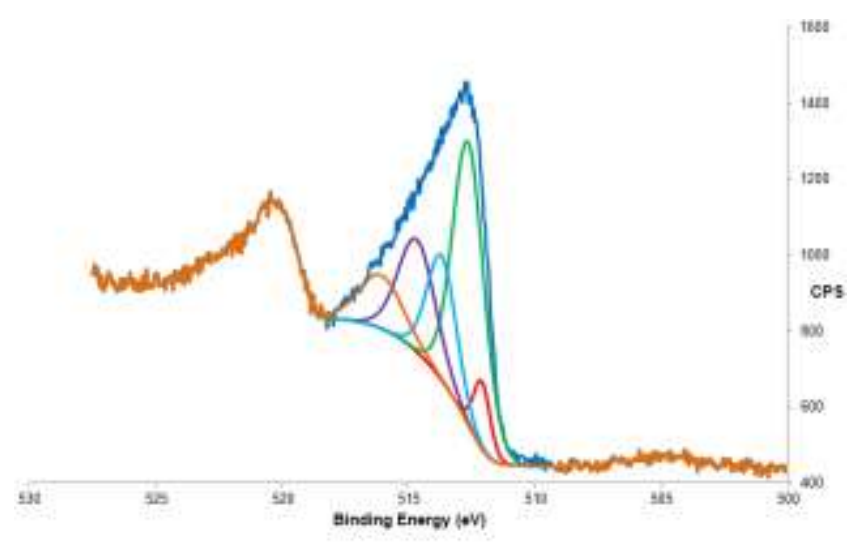

Figure 2. Peak fitting of vanadium 2 p3/2 region of XPS of V(IV)$25 \mathrm{C}-\mathrm{H}_{2}$ states of vanadium present in the material, but an overall reduction has occurred on hydrogenation. Simulation shows that a vanadium (IV) species is now present as demonstrated by the emission at $516.1 \mathrm{eV}$, which is close to the emission of V(IV) at 516.3 $\mathrm{eV}$ for $\mathrm{V}_{2} \mathrm{O}_{4}{ }^{23}$ The two minor simulated emissions at $515.3 \mathrm{eV}$ and $514.3 \mathrm{eV}$ are similar in intensity and can both be attributed to V(III) species as they are both close to the emission reported for $\mathrm{V}_{2} \mathrm{O}_{3}$ at $515.7,{ }^{23}$ suggesting that these are two different $\mathrm{V}$ (III) species with slightly different environments. The emission with the largest intensity falls at $513.8 \mathrm{eV}$ and can also be attributed to a V(III) species by comparison to the emission at $513.9 \mathrm{eV}$ reported for $\mathrm{V}(\mathrm{OH})_{3}{ }^{24}$ The small emission at $512.2 \mathrm{eV}$ can be assigned to $\mathrm{V}(0)^{25}$ and demonstrates that excessive reduction leads to formation of $\mathrm{V}$ metal. The oxidation state distribution of $\mathrm{V}(\mathrm{IV})-25 \mathrm{C}-\mathrm{H}_{2}$ is similar to that observed for lower valent vanadium hydride gels synthesized previously by our group from V(III) alkyl precursors. ${ }^{9 c}$ Overall this demonstrates that this important new hydrogen storage material can be readily accessed indirectly by reduction of more conveniently prepared V(IV) aryl species as opposed to directly from more elusive and expensive V(III) alkyl compounds, while also highlighting the flexibility of oxidation states in this class of materials, properties that can be exploited for electrochemical energy storage or catalysis.

\section{Electrochemical assessment}

Because $\mathrm{V}(\mathrm{IV})-25 \mathrm{C}-\mathrm{H}_{2}$ contains a variety of $\mathrm{V}$ oxidation states the further characterization by electrochemical methods and possible exploitation as a cathode material is warranted. The electrochemical properties of $\mathrm{V}(\mathrm{IV})-25 \mathrm{C}-\mathrm{H}_{2}$ were thus assessed using a variety of electrochemical methods. The potential window used for these studies was slightly different to what is typical for $\mathrm{V}$ (IV) materials as V(IV)-25C- $\mathrm{H}_{2}$ became unstable above $3.2 \mathrm{~V}$ and so we were unable to reach the maximum $4 \mathrm{~V}$ normally employed for measurement of other vanadium compounds. ${ }^{15,26}$ For this reason we first tested a $\mathrm{VO}_{2}$ commercial powder as an external standard by which to compare the electrochemical behavior.

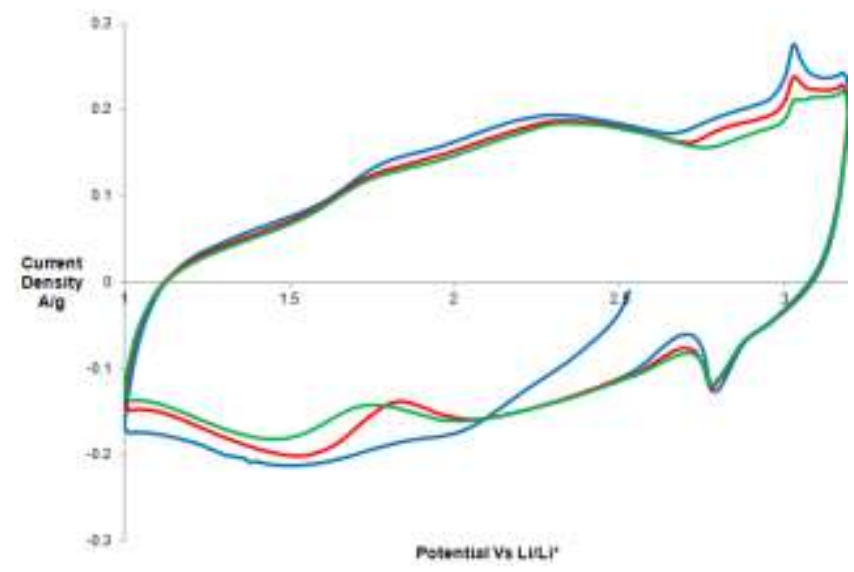

Figure 3. Cyclic voltammetry: potential range of $1.0-3.2 \mathrm{~V}$ vs $\mathrm{Li} / \mathrm{Li}^{+}$standard electrode potential V(IV)-25C- $\mathrm{H}_{2}$ at a sweep rate of $0.5 \mathrm{mVs}^{-1}: 1$ st cycle (blue), 2nd cycle (red) and 3rd cycle (green)

Cyclic voltammetry (CV) measurements of V(IV)-25C- $\mathrm{H}_{2}$ and $\mathrm{VO}_{2}$ were carried out at a variety of different sweep rates. Figure S9 shows the CV data for both V(IV)-25C- $\mathrm{H}_{2}$ and the standard $\mathrm{VO}_{2}$ powder at the lowest scan rate of $0.5 \mathrm{mVs}^{-1}$ as these conditions reveal the most accurate picture of redox processes occurring within the material. Figure 3 shows the first 3 cycles of the $\mathrm{CV}$ of $\mathrm{V}(\mathrm{IV})-25 \mathrm{C}-\mathrm{H}_{2}$ measured at a $0.5 \mathrm{mV} \mathrm{s}^{-1}$ scan rate. The first cathodic sweep of $\mathrm{V}(\mathrm{IV})-25 \mathrm{C}-\mathrm{H}_{2}$ shows a single broad peak in the 
first cathodic sweep from 2.5-1.0 V, displaying no distinct features. This is explained by the amorphous nature of the material confirmed by the PXRD, with XPS data revealing multiple oxidation states between $\mathrm{V}(0)$ and $\mathrm{V}(\mathrm{IV})$. Thus the wide variation of redox sites and the amorphous structure of the material produce the broad peak observed rather than resolved peaks at specific potentials. The reference material $\mathrm{VO}_{2}$ (figure $\mathrm{S} 10$ ) displays 2 peaks on the initial cathodic sweep at $2.45 \mathrm{~V}$ and $1.7 \mathrm{~V}$. The first peak is referenced as the insertion potential for $\mathrm{Li}$ insertion into $\mathrm{VO}_{2}$ reducing $\mathrm{V}$ (IV) to $\mathrm{V}$ (III). ${ }^{15 a},{ }^{15 c}, 26$ In the first initial anodic sweep of $\mathrm{V}(\mathrm{IV})-25 \mathrm{C}-\mathrm{H}_{2}$ again the current produces a broad signal which can be interpreted as two broad peaks centered at 1.7 and $2.3 \mathrm{~V}$, with the addition of a more resolved peak present at $3.0 \mathrm{~V}$. The anodic sweep of $\mathrm{VO}_{2}$ also produces three peaks at $2.3,2.8$ and $3.05 \mathrm{~V}$. The best resolved peak at $2.8 \mathrm{~V}$ represents what is normally observed in V(IV) materials, suggesting the other peaks at $2.3 \mathrm{~V}$ and $3.05 \mathrm{~V}$ in the $\mathrm{VO}_{2}$ powder most likely represent oxidation from $\mathrm{V}$ (II) to (VIII) and V(IV) to V(V), respectively. This indicates that the same transitions occur in V(IV)-25C- $\mathrm{H}_{2}$ but at lower potential values then that of the respective oxide. The second cycle produced a more informative picture of the electrochemical nature of the material. The cathodic sweep of V(IV)$25 \mathrm{C}-\mathrm{H}_{2}$ now displays three peaks centered at 2.7, 2.1 and $1.6 \mathrm{~V}$, respectively. The first peak is well resolved whereas the two subsequent peaks are still broad but now show more resolved peaks than previously. This is most likely because more vanadium species are now present at the same oxidation state during cycling. The appearance of a small new peak at $2.85 \mathrm{~V}$ in the $\mathrm{VO}_{2}$ powder on the second cathodic sweep confirms this new peak as the reduction back of $\mathrm{V}(\mathrm{V})$ to $\mathrm{V}(\mathrm{IV})$. The comparison of $\mathrm{V}(\mathrm{IV})-25 \mathrm{C}-\mathrm{H}_{2}$ to the $\mathrm{VO}_{2}$ reference allows the interpretation that the three peaks represent successive reductions from $\mathrm{V}(\mathrm{V})$ to $\mathrm{V}$ (II) at slightly lower potential values then those of the respective oxide. This is possibly due to the difference in the hydride ligand environment in $\mathrm{V}$ (IV)-25C- $\mathrm{H}_{2}$ compared to the oxide in the standard, which have been shown to affect the redox potentials of a compound.

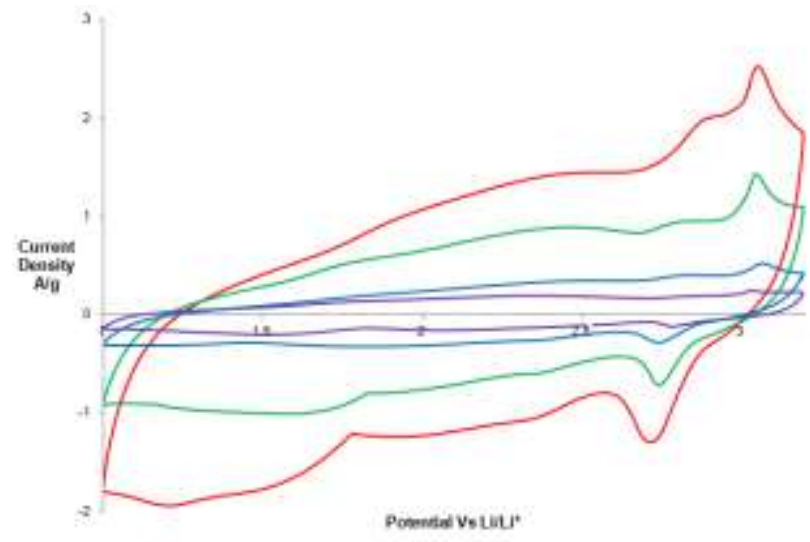

Figure 4. Cyclic voltammetry: potential range of $1.0-3.2 \mathrm{~V}$ vs $\mathrm{Li} / \mathrm{Li}^{+}$standard electrode potential at various sweep rates of V(IV)-25C-H $\mathrm{H}_{2}: 0.5 \mathrm{mVs}^{-1}$ (purple), $1 \mathrm{mVs}^{-1}$ (blue), $2 \mathrm{mVs}^{-1}$ (green) and $5 \mathrm{mVs}^{-1}$ (red)

Figure 4 shows the $\mathrm{CV}$ of $\mathrm{V}(\mathrm{IV})-25 \mathrm{C}-\mathrm{H}_{2}$ taken at a variety of different scan rates and it is clear that the current produced is approximately proportional to the increase in sweep rate as by doubling the sweep rate, the current produced is also doubled. This is typical of a capacitive response in which current is directly proportional to the sweep rate, whereas insertion based mechanisms are proportional to the square root of the sweep rate. ${ }^{17}$ The capacity of $\mathrm{V}(\mathrm{IV})-25 \mathrm{C}-\mathrm{H}_{2}$ was assessed by galvanostatic charge discharge analysis over the course of 50 cycles and is shown in Figure 5. V(IV)-25C- $\mathrm{H}_{2}$ has an initial capacity of $111 \mathrm{mAhg}^{-1}$, which increases upon its first full charge to a peak capacity of 131 $\mathrm{mAhg}^{-1}$. The reason for the increase in capacity after the first cycle may be due to the oxidation of vanadium centers that where initially present in the lower oxidation states to higher oxidation states, allowing a higher concentration of lithium ions to be incorporated to balance the increased number of higher oxidation state vanadium ions upon discharge. After carrying out 50 cycles, the capacity dropped by $64 \%$ to $47 \mathrm{mAhg}^{-1}$. These results indicate that despite showing an initial capacity comparable to previous published $\mathrm{VO}_{2}$ cathode materials which produce capacities around $160-250 \mathrm{mAhg}^{-1},{ }^{15 a}, 27$ the recyclability of the material is not sufficient enough to maintain its performance with repeated cycling. However, these oxide materials have been developed in order to maximize their performance as a cathode material. When comparing these results to those of bulk $\mathrm{VO}_{2}$, which produces initial capacities around $128 \mathrm{mAh} / \mathrm{g}$ which subsequently drop to $58 \mathrm{mAhg}$ ${ }^{1}$ at a lower current density, ${ }^{28}$ this demonstrates an overall improvement shown by use of the hydride ligand in the bulk state. Given the improvement relative to bulk $\mathrm{VO}_{2}$ with better tailored morphologies, it is possible that the same could be achieved using the much lighter hydride ligand to produce improved capacity and recycling performance.

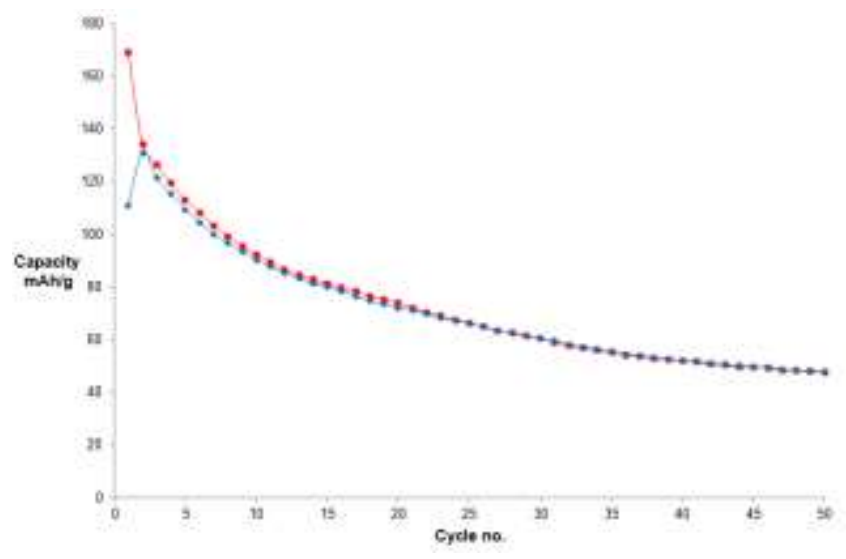

Figure 5.50 cycles charge (red) and discharge (blue) capacity data for $\mathrm{V}(\mathrm{IV})-25 \mathrm{C}-\mathrm{H}_{2}$ at $1 \mathrm{mAcm}^{-2}$

Figures 6 and S11 show the Nyquist plots for both V(IV)-25C$\mathrm{H}_{2}$ and $\mathrm{VO}_{2}$, respectively They demonstrate the impedance spectra prior to initial discharge and after the final charge on completion of the 50 cycles. Both materials show a semicircle present at the high frequency region of plot, followed by a Warburg tail. The

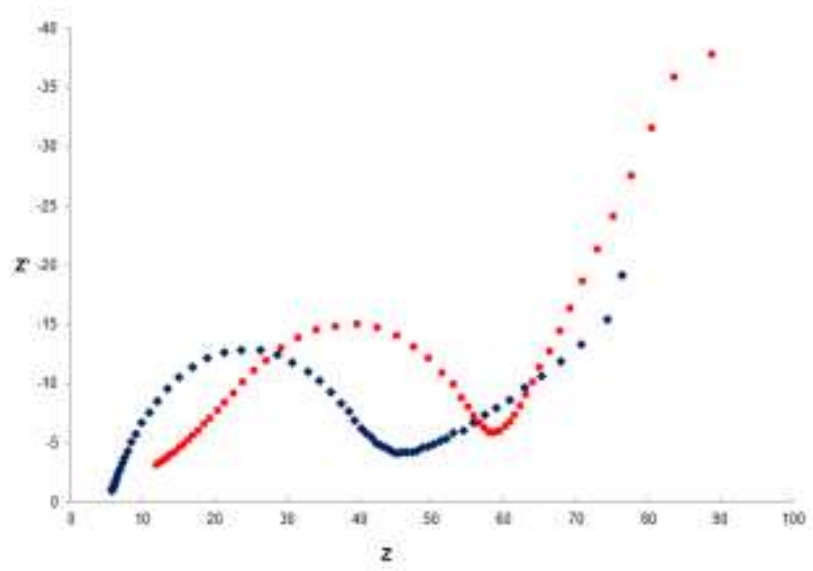

Figure 6. EIS spectra of V(IV)-25C- $\mathrm{H}_{2}$ initial (blue) and after (red) cycle completion 
initial semicircle is of key importance as it indicates the charge transfer resistance of the material. The Warburg tail (W) is associated with lithium diffusion in the bulk of the active material. The high frequency intercept of the semicircle is related to the electrolyte resistance $\left(\mathrm{R}_{\mathrm{e}}\right)$ and the diameter of the semicircles indicates the charge transfer resistance $\left(R_{\mathrm{ct}}\right)$ for the material. Using the diameter of the semicircles, we calculated the initial values of $R_{c t}$ to be $38.41 \Omega$ and $44.39 \Omega$ for $\mathrm{V}(\mathrm{IV})-25 \mathrm{C}-\mathrm{H}_{2}$ and $\mathrm{VO}_{2}$, respectively, which rises to $46.67 \Omega$ and $44.58 \Omega$ after completing 50 cycles. This confirms that the $\mathrm{V}(\mathrm{IV})-25 \mathrm{C}-\mathrm{H}_{2}$ has a charge transfer resistance that is initially lower relative to that of our reference $\mathrm{VO}_{2}$ powder but after recycling the resistance increases so that it is larger than the $\mathrm{VO}_{2}$ commercial powder, which barely increases after 50 cycles. This is possibly due to the formation of electrode/electrolyte interface layer, making the diffusion of ions across the separator more difficult. These improvements in electron conductivity are essential, as it significantly affects the performance of the battery material. Improved electron conductivity allows the production of higher currents without losing capacity or cycle life. This is because the material is able to easily transport electrons to and from the vanadium centers allowing the charges to separate and recombine much more quickly and efficiently within the cathode. ${ }^{29}$

\section{Hydrogen Storage Properties}

The vanadium hydride materials V(IV)-100 and V(IV)-25C- $\mathrm{H}_{2}$ were tested for room temperature hydrogen storage to compare their activity to V(III) alkyl hydride gels previously synthesized by our group. ${ }^{9 \mathrm{c}}$ Hydrogen PCT adsorption-desorption isotherms were thus recorded at $298 \mathrm{~K}$ and compared to standard isotherm of AX-21 recorded under the same conditions at 2-3 mmol total adsorption of $\mathrm{H}_{2}$ for accuracy. The initial material V(IV)-100 reached a maximum of $2.1 \mathrm{wt} \%$ at 130 bar and $25{ }^{\circ} \mathrm{C}$ without saturation as shown in figure 7 . After solid state hydrogenation to make $\mathrm{V}(\mathrm{IV})-25 \mathrm{C}-\mathrm{H}_{2}$, the hydrogen storage performance improved to reach a maximum of $5.8 \mathrm{wt} \%$ at 130 bar and $25^{\circ} \mathrm{C}$ shown in figure 7. The adsorption isotherm increases in a linear fashion

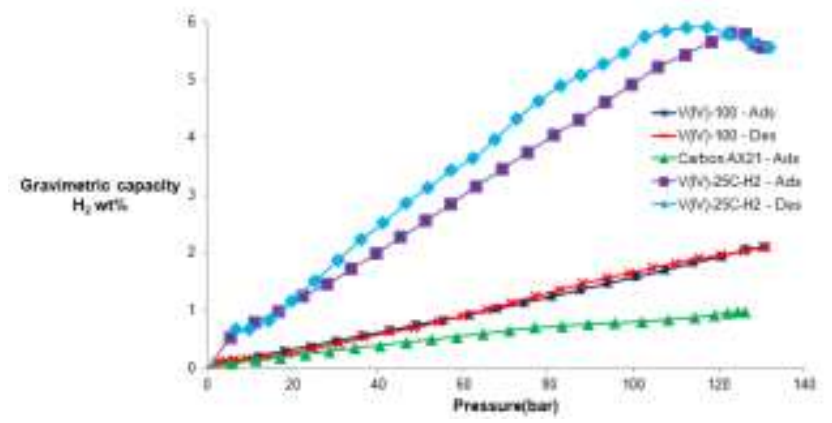

Figure 7. Hydrogen adsorption-desorption recorded at $25{ }^{\circ} \mathrm{C}$ measured between 2-3 mmol total $\mathrm{H}_{2}$ adsorption per isotherm at 130 bar for consistency

with increasing pressure until it reaches 120 bar where the isotherm reaches saturation, as demonstrated by a plateau in both the adsorption and desorption isotherms, although there is some hysteresis and a slight decrease in capacity after saturation. Since saturation of hydrogen uptake is observed we can be confident in the accuracy of the measurements as any error introduced from inaccurate volume calibrations or a leak would lead to virtual adsorption in the isotherm, meaning that saturation would never be reached. Furthermore, saturation with hysteresis was also observed at 120 bar in our previously studied V(III)-hydride materi- al, ${ }^{9 \mathrm{c}}$ although the $5.8 \mathrm{wt} \%$ at 120 bar capacity for $\mathrm{V}(\mathrm{IV})-25 \mathrm{C}-\mathrm{H}_{2}$ is a slight improvement over the $5.3 \mathrm{wt} \%$ at the same pressure for this previously studied V(III) material. The volumetric capacity of $\mathrm{V}(\mathrm{IV})-25 \mathrm{C}-\mathrm{H}_{2}$ is $79.77 \mathrm{kgH}_{2} \mathrm{~m}^{-3}$ based on the measured density of the material of $1.37 \mathrm{~g} \mathrm{~cm}^{-3}$. While the stoichiometry of this material is complex, for a hypothetical material based on pure phase $\mathrm{VH}_{4}$, up to $4 \mathrm{H}_{2}$ could bind according to the eighteenelectron rule, or $5 \mathrm{H}_{2}$ in the case of $\mathrm{VH}_{3}$. This gives a theoretical maximum performance of $12.7 \mathrm{wt} \%$ for $\mathrm{VH}_{4}$ and $15.7 \mathrm{wt} \%$ for $\mathrm{VH}_{3}$, calculated from the final mass at saturation of $\mathrm{VH}_{12}$ and $\mathrm{VH}_{13}$, respectively. Although the measured $5.8 \mathrm{wt} \%$ capacity for $\mathrm{V}$ (IV)-25C- $\mathrm{H}_{2}$ is lower than this theoretical maximum, this is not surprising considering that there is still hydrocarbon present in the material and that the material is a mixture of different vanadium oxidation states, some of which may not absorb $\mathrm{H}_{2}$. Although both V(III) and V(IV) are confirmed by XPS and expected to bind $\mathrm{H}_{2}$, on the basis of pure $\mathrm{VH}_{4}, 1 \mathrm{H}_{2}$ per $\mathrm{V}$ gives an expected gravimetric capacity of $3.6 \mathrm{wt} \%$ and $2 \mathrm{H}_{2}$ per $\mathrm{V}$ would amount to 7.3 $\mathrm{wt} \%$. Therefore on the basis of the $5.8 \mathrm{wt} \%$ plateau it is reasonable to assume that some $\mathrm{V}$ centers bind $1 \mathrm{H}_{2}$ and some bind $2 \mathrm{H}_{2}$, similar to what we have determined for previous $\mathrm{Ti},{ }^{9 \mathrm{a}} \mathrm{Cr},{ }^{9 \mathrm{~b}}$ and $\mathrm{V}^{9 \mathrm{c}}$ materials. Because the $2.2 \mathrm{~m}^{2} / \mathrm{g}$ surface area of $\mathrm{V}(\mathrm{IV})-25 \mathrm{C}$ $\mathrm{H}_{2}$ is very low relative to $\mathrm{AX}-21$, which has a surface area of $2800 \mathrm{~m}^{2} / \mathrm{g}$ and much lower adsorption than V(IV)-25C- $\mathrm{H}_{2},{ }^{19}$ the hydrogen adsorption of $5.8 \mathrm{wt} \%$ can not be due to physisorption but most likely from the Kubas interaction of $\mathrm{H}_{2}$, as directly observed previously by high-pressure Raman spectroscopy for $\mathrm{H}_{2}$ adsorption by $\mathrm{TiH}_{3}{ }^{9 \mathrm{a}}, \mathrm{CrH}_{3},{ }^{9 \mathrm{~b}}$ and $\mathrm{VH}_{3} .{ }^{9 \mathrm{c}}$ However more physical studies are required on the adsorption mechanism as the nitrogen adsorption determined surface areas may not reflect the surface area available to the much smaller $\mathrm{H}_{2}$ molecule, and there is also the possibility of $\mathrm{H}_{2}$ shuttling through the material by a "bind and rotate" mechanism. Vanadium oxamide materials studied previously by our group also possess low surface areas in the range of $9-30 \mathrm{~m}^{2} / \mathrm{g}$ and store hydrogen via the Kubas interaction as confirmed by Raman measurements, but these materials have capacities of only $0.87 \mathrm{wt} \%$ at 85 bar and $25{ }^{\circ} \mathrm{C}$, likely due to the bulky oxamide linking ligands which could hinder $\mathrm{H}_{2}$ coordination while also adding excess weight, thus cutting into gravimetric performance. ${ }^{30}$

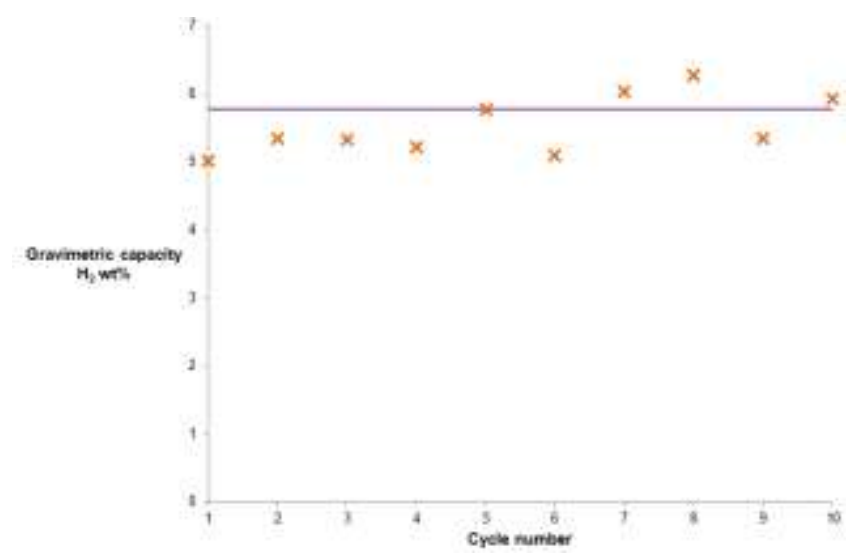

Figure 8. Cycle of 10 hydrogen adsorption and desorption isotherms up to 130 bar recorded at $25{ }^{\circ} \mathrm{C}$ for V(IV)-25C-H2. Errors are estimated at $\pm 0.07 \mathrm{wt} \%$.

A cycling measurement was carried out on for $\mathrm{V}(\mathrm{IV})-25 \mathrm{C}-\mathrm{H}_{2}$ to see if activity was affected by repeated adsorption and desorption of hydrogen. During the cycling measurement the sample was dosed with hydrogen in increasing pressure increments between 0 and 130 bar where the capacity at 130 bar was recorded, this was followed by a decrease in pressure back to 0 bar. This cycle was 
repeated 10 times with a five minute vacuum step at $25{ }^{\circ} \mathrm{C}$ in between each cycle. The capacity at 130 bar for each cycle is shown in figure 8 . The average performance over the 10 cycles was $5.77 \mathrm{wt} \%$ and the capacity did not decrease from repeated hydrogen adsorption/desorption cycles.

In previous work, the enthalpy of hydrogen adsorption for a V(III) alkyl hydride gel was determined directly by isothermal calorimetry as $+0.52 \mathrm{~kJ} \mathrm{~mol}^{-1} \mathrm{H}_{2}$ over the pressure range of the experiment between 0 and 130 bar. ${ }^{9 \mathrm{c}}$ We also reported the total enthalpy of hydrogen adsorption for the analogous $\mathrm{Cr}$ (III) alkyl hydride $\left(+0.37 \mathrm{~kJ} \mathrm{~mol}^{-1} \mathrm{H}_{2}\right) .{ }^{9 \mathrm{~b}}$ In both of these systems the directly measured enthalpy of binding of hydrogen by the Kubas interaction is not in the expected $20-40 \mathrm{~kJ} \mathrm{~mol}^{-1}$ range exhibited by classical Kubas complexes, despite confirming Kubas binding by high pressure Raman measurements. This supports the mechanism put forward by our group and supported by computations that the hydrogen binding is thermodynamically neutral because the enthalpy of hydrogen binding is offset by an endothermic process of pressure induced deformation of the material springing open new binding sites with increasing pressure. ${ }^{31}$ With Henry's adsorption and an expected entropy of $\mathrm{H}_{2}$ binding of $-100 \mathrm{JK}^{-1}$ this allows reversible adsorption to occur with increasing pressure. ${ }^{11 \mathrm{~b}}$ While the enthalpy of $\mathrm{H}_{2}$ adsorption has not yet been directly measured for $\mathrm{V}(\mathrm{IV})-25 \mathrm{C}-\mathrm{H}_{2}$, because of the similarities in performance and XPS, we expect it to be in a similar range to the values reported for the $\mathrm{Cr}$ (III) hydride and V(III) hydride materials.

\section{Conclusion}

A vanadium hydride gel was prepared by thermal treatment of a solution of tetraphenyl vanadium (IV) at $100{ }^{\circ} \mathrm{C}$ followed by hydrogenation of the material in order to exploit the low mass of the hydrogen ligand for improved gravimetric energy storage. Characterization of the material shows that it is amorphous and consists predominantly of vanadium hydride species in oxidation states between III and IV. The material reversibly stores $5.8 \mathrm{wt} \%$ hydrogen at 130 bar and $25{ }^{\circ} \mathrm{C}$ and is also significantly more convenient, safer, and less expensive to synthesize than previous vanadium alkyl hydrides reported previously by our group. As anticipated from the valency of the vanadium centers and the low mass of the hydride ligands, the material possesses promising redox peak capacity of $131 \mathrm{mAhg}^{-1}$ at a discharge rate of 1.0 $\mathrm{mAcm}^{-2}$, the capacity decreases with repeated cycling until it reaches $47 \mathrm{mAhg}^{-1}$ after 50 cycles, comparable to bulk phase $\mathrm{VO}_{2}$. While these numbers are approaching practical performance for onboard systems at an affordable cost, this material does not yet present enough recyclability to be utilized as a useful secondary lithium battery material, however improvements in synthesis and nanostructuring could further improve hydrogen storage performance while also leading to a more effective battery cathode material with improved recyclability performance.

\section{ASSOCIATED CONTENT}

\section{Supporting Information}

Additional figures including IR, $\mathrm{N}_{2}$ adsorption-desorption, PXRD, TGA/DTA, XPS, cyclic voltammetry and EIS spectra can be found in the supporting information. This material is available free of charge via the Internet at http://pubs.acs.org.

\section{AUTHOR INFORMATION}

\section{Corresponding Author}

david.antonelli@southwales.ac.uk

\section{ACKNOWLEDGMENT}

The authors acknowledge the University of South Wales for funding.

\section{REFERENCES}

1. King, R. B., Coord. Chem. Rev. 2000, 200-202 (0), 813-829.

2. Wang, X.; Andrews, L., J. Phys. Chem. A. 2003, 107 (4), 570-578.

3. Ozin, G. A.; McCaffrey, J. G., J. Am. Chem. Soc. 1984, 106 (3), 807809.

4. Chertihin, G. V.; Andrews, L., J Phys Chem. 1995, 99 (32), 1213112134 .

5. Miller, A. E. S.; Feigerle, C. S.; Lineberger, W. C., J Chem. Phys. 1986, 84 (8), 4127-4131.

6. Chertihin, G. V.; Andrews, L., J. Am. Chem. Soc. 1994, 116 (18), 8322-8327.

7. Maeland, A. J.; Gibb, T. R. P.; Schumacher, D. P., J. Am. Chem. Soc. 1961, 83 (17), 3728-3729.

8. Reilly, J. J.; Wiswall, R. H., Inorg. Chem. 1970, 9 (7), 1678-1682.

9. (a) Hoang, T. K. A.; Morris, L.; Reed, D.; Book, D.; Trudeau, M. L.; Antonelli, D. M., Chem. Mater. 2013, 25 (23), 4765-4771; b) Morris, L.; Trudeau, M. L.; Reed, D.; Book, D.; Antonelli, D. M., Phys. Chem. Chem. Phys. 2015, 17 (14), 9480-9487; c) Morris, L.; Trudeau, M.; Reed, D.; Book, D.; Antonelli, D. M., Chem. Phys. Chem. 2016 doi.org/10.1002/cphc.201501093.

10. a) Kubas, G. J., Chem. Rev, 2007, 107, 4152-4205; b) Bhatia, S. K., Myers, A.L. Langmuir 2006, 22, 1688-1700; c) Zhao, Y., Kim, Y.-H., Dillon, A. C., Heben, M. J., Zhang, S. B. Phys. Rev. Lett. 2005, 94. d) Yildirim T., Ciraci, S. Phys Rev Let 2005, 94, 175501.

11. a) Andalibi, M. R., Qajar, A., Foley H. J. Phys. Chem C. 2015, 119 , 21314; b) Abrecht, D. G., Fultz, B. J. Phys. Chem. C 2012, 116, 2224522252.

12. (a) Zhou, X.; Cui, C.; Wu, G.; Yang, H.; Wu, J.; Wang, J.; Gao, G., J. Power Sources. 2013, 238, 95-102; (b) Ban, C.; Chernova, N. A.; Whittingham, M. S., Electrochem Comm. 2009, 11 (3), 522-525.

13. (a) Nethravathi, C.; Viswanath, B.; Michael, J.; Rajamath, M., Carbon. 2012, 50 (13), 4839-4846; (b) Ganganagappa, N.; Siddaramanna, A., Mater Charact 2012, 68, 58-62; (c) Chen, Z.; Gao, S.; Jiang, L.; Wei, M.; Wei, K., Mater Chem Phys. 2010, 121 (1-2), 254-258.

14. Brezesinski, T.; Wang, J.; Tolbert, S. H.; Dunn, B., Nat Mater., 2010, 9 (2), 146-151.

15. Wang, J.; Polleux, J.; Lim, J.; Dunn, B., J Phys. Chem. C. 2007, 111 (40), 14925-14931.

16. Buijink, J. K. F.; Meetsma, A.; Teuben, J. H., Organomet. 1993, 12 , 2004-2005.

17. Barker, G. K.; Lappert, M. F.; Howard, J. A. K., J. Chem. Soc, Dalton Trans. 1978, (7), 734-740.

18. Mowat, W.; Shortland, A.; Yagupsky, G.; Hill, N. J.; Yagupsky, M.; Wilkinson, G., J. Chem Soc, Dalton Trans. 1972, (4), 533-542.

19. Chahine, R; Bernard, P. Assessment of Hydrogen Storage on Different Carbons; 2001, pp 104-107.

20. Kaesz, H. D.; Saillant, R. B., Chem. Rev. 1972, 72 (3), 231-281.

21. Nefedov, V. I.; Salyn, Y. V.; Leonhardt, G.; Scheibe, R., J. Electron Spec and Relat Phenom. 1977, 10 (2), 121-124.

22. Horvath, B.; Strutz, J.; Geyer-Lippmann, J.; Horvath, E. G., Z. Anorg. Allg. Chem. 1981, 483 (12), 181-192.

23. Colton, R. J.; Guzman, A. M.; Rabalais, J. W., Journal of Applied Physics. 2008, 49 (1), 409-416.

24. F. Werfel, O. Brümmer, Phys. Scr. 1983, 28, 92.

25. Myers, C. E.; Franzen, H. F.; Anderegg, J. W., Inorg. Chem. 1985, 24 (12), 1822-1824.

26. Zhao, Q.; Jiao, L.; Peng, W.; Gao, H.; Yang, J.; Wang, Q.; Du, H.; Li, L.; Qi, Z.; Si, Y.; Wang, Y.; Yuan, H., J. Power Sources. 2012, 199, 350-354.

27. (a) Subba Reddy, C. V.; Walker Jr, E. H.; Wicker Sr, S. A.; Williams, Q. L.; Kalluru, R. R., Curr. Appl. Phys. 2009, 9 (6), 1195-1198; (b) Wang, W.; Jiang, B.; Hu, L.; Lin, Z.; Hou, J.; Jiao, S., Journal of Power Sources. 2014, 250 (0), 181-187; (c) Rahman, M. M.; Wang, J.-Z.; Idris, N. H.; Chen, Z.; Liu, H., Electrochim. Acta. 2010, 56 (2), 693-699.

28. Wang, Q.; Pan, J.; Li, M.; Luo, Y.; Wu, H.; Zhong, L.; Li, G., J.Mater Sci \& Technol. 2015, 31 (6), 630-633. 
29. (a) Whittingham, M. S., Chem. Rev. 2004, 104 (10), 4271-4302; (b) Daniel, C.; Mohanty, D.; Li, J.; Wood, D. L., AIP Conference Proceed. 2014, 1597, 26-43.

30. Hoang, T. K. A.; Hamaed, A.; Moula, G.; Aroca, R.; Trudeau, M.; Antonelli, D. M., J. Am. Chem. Soc. 2011, 133 (13), 4955-4964.
31. Skipper, C. V. J.; Antonelli, D. M.; Kaltsoyannis, N., J. Phys. Chem. C. 2012, 116 (36), 19134-19144.

SYNOPSIS TOC (Word Style "SN_Synopsis_TOC"). If you are submitting your paper to a journal that requires a synopsis graphic and/or synopsis paragraph, see the Instructions for Authors on the journal's homepage for a description of what needs to be provided and for the size requirements of the artwork.

To format double-column figures, schemes, charts, and tables, use the following instructions:

Place the insertion point where you want to change the number of columns

From the Insert menu, choose Break

Under Sections, choose Continuous

Make sure the insertion point is in the new section. From the Format menu, choose Columns

In the Number of Columns box, type 1

Choose the $\mathbf{O K}$ button

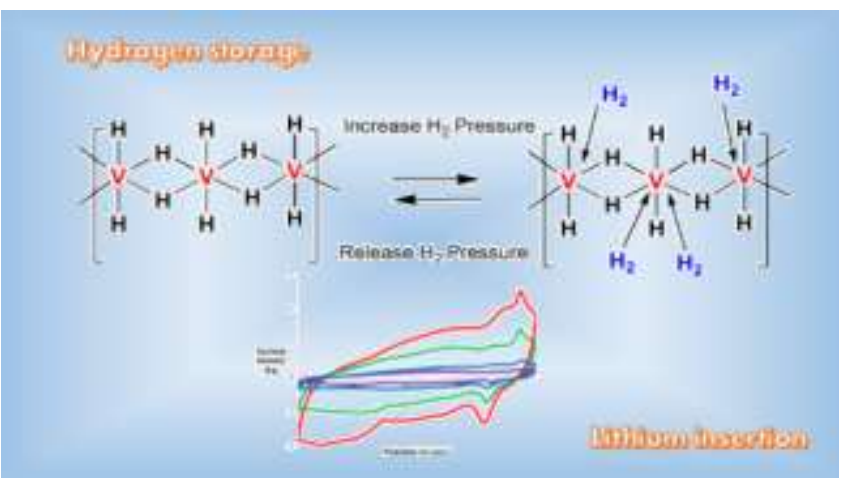

